Title of Renewal Grant Proposal (Years 07-09):

Malignant Transformation of Human Fibroblasts by Neutrons and Gamma Radiation: Relationship to Mutations Induced

D.O.E. Grant DE-FG02-87-ER60524-04-06

\section{MALIGNANT TRANSFORMATION \\ OF DIPLOID HUMAN FIBROBLASTS \\ BY TRANSFECTION OF ONCOGENES}

(ORIGINAL TITLE)

Division of Biological and Environmental Research Department of Energy

J. Justin McCormick, Ph.D., Principal Investigator

\author{
Carcinogenesis Laboratory - Fee Hall \\ Department of Microbiology and Department of Biochemistry \\ Michigan State University, East Lansing, MI 48824-1316
}

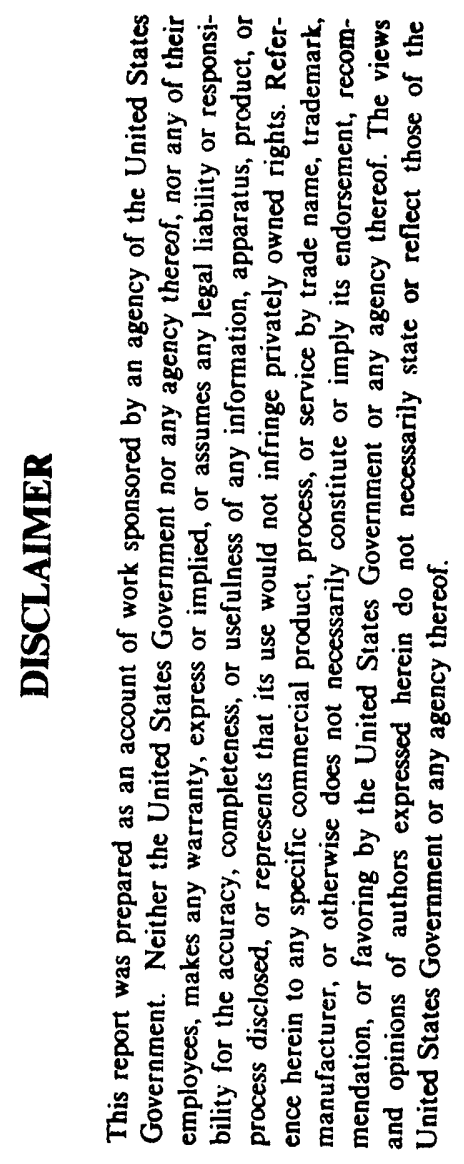

BISTRIBUTION OF THIS OOCUMENT is
Submitted 


\section{PART TWO: COMPREHENSIVE PROGRESS REPORT}

I. Period Covered..........................................

II. Publications Resulting from Research Supported by this Grant......3

III. Overview of Research Accomplished.......................

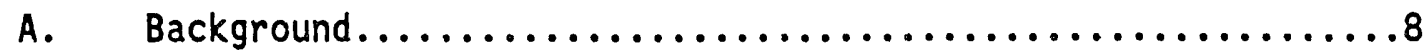

B. Malignant Transformation of MSU-1.1 Cells by Gamma Radiation.........................................9

C. Correlation between Levels of ras Expression and Tumorigenicity....................................10

D. Relation between Specific Types of Tumors and Specific ras Oncogene Expression.............................

E. Correlation between Genetic Changes and Malignancy.........13

F. Transformation of MSU-1.1 Cells by the sis Oncogene........14

G. Malignant Transformation of MSU-1.0 Cells.............15

H. Correlation of Urokinase Plasminogen Activator with the Malignant Phenotype............................17

I. Two Dimensional Gel Electrophoresis Studies..............17

J. Correlation between Proteinase Activity and Malignancy.....17

IV. Draft Copies of Six Manuscripts in Preparation................18

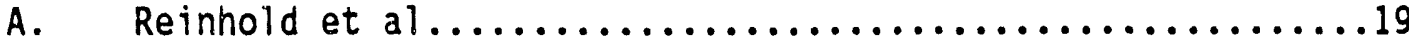
B. Louden et al .....................................
C. Louden, Dunstan et al ...........................85
D. Wray et al.......................................

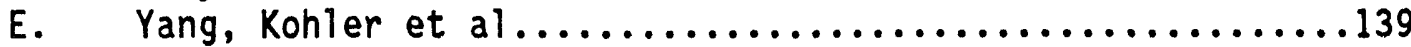

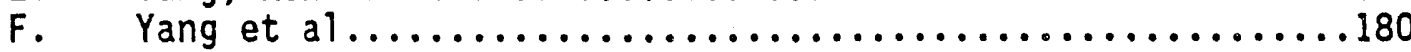

V. Relationship Between the Research Accomplished during the Past Three Years and the Objectives for the Coming Three Years and Terminology Used in this Proposal......................229

VI. Postdoctoral Tenures Completed and Graduate Students Trained...230 


\section{COMPREHENSIVE PROGRESS REPORT}

DE-FG02-87-ER60524-01

I. PERIOD COVERED: JULY 1, 1989 - JUNE 30, 1992

\section{PUBLICATIONS ARISING FROM RESEARCH SUPPORTED IN WHOLE OR IN PART BY THIS GRANT SINCE JULY 1, 1989}

A. Papers in Refereed Journals:

1. H. J. Palmer, V. M. Maher, and J. J. McCormick. The effect of retinoids on growth factor-induced anchorage independent growth of human fibroblasts. In Vitro Cell \& Dev. Biol. 25, 1009-1015 (1989).

2. T. R. Fox, A. M. Schumann, P. G. Watanabe, B. L. Yano, V. M. Maher, and J. $\mathrm{J}$. McCormick. Mutational analysis of the H-ras oncogene in spontaneous $\mathrm{C} 57 \mathrm{BL} / 6 \mathrm{X} \mathrm{C}_{3} \mathrm{H} / \mathrm{He}$ mouse liver tumors and tumors induced with genotoxic and nongenotoxic hepatocarcinogens. Cancer Res. 50, 4014-4019 (1990).

3. D. M. Wilson, D. Yang, J. E. Dillberger, S. E. Dietrich, V. M. Maher, and J. J. McCormick. Malignant transformation of human fibroblasts by a transfected N-ras oncogene. Cancer Res. 50, 5587-5593 (1990).

4. D. G. Fry, L. D. Milam, J. E. Dillberger, V. M. Maher, and J. J. McCormick. Malignant transformation of infinite life span human

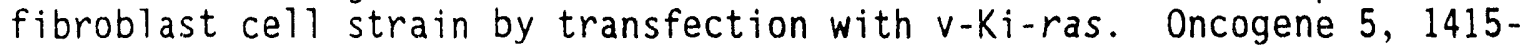
1418 (1990).

5. J. Jankun, V. M. Maher, and J. J. McCormick. Malignant transformation of human fibroblasts is correlated with increased activity of receptor-bound plasminogen activator. Cancer Res. 51, 1221-1226 (1991).

6. T. L. Morgan, D. Yang, D. G. Fry, P. J. Hurlin, S. K. Kohler, V. M. Maher, and J. J. McCormick. Characteristics of an infinite life span diploid human fibroblast cell strain and a near-diploid strain arising from a clone of cells expressing a transfected $v$-myc oncogene. Exp. Cell Res. $197,125-136$ (1991).

7. D. Yang, C. Louden, D. S. Reinhold, S. K. Kohler, V. M. Maher, and J. J. McCormick. Malignant transformation of human fibroblast cell strain MSU-

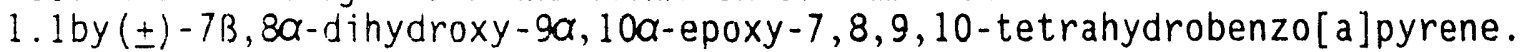
Proc. Nat1. Acad. Sci. (U.S.A.) 89:2237-2241 (1992)

8. M. J. Miller, V. M. Maher, and J. J. McCormick. Analysis of human fibroblasts transformed by ras oncogenes using quantitative twodimensional gel electrophoresis. Electrophoresis (in press, 1992).

9. Wang, Q., V. M. Maher, and J. J. McCormick. Mammalian expression vectors with modulatable promoters and two multiple cloning sites. Gene (in press, 1992). 
B. Published Monographs, Review Articles, or Chapters in Books:

1. J. J. McCormick, D. G. Fry, P. J. Hurlin, T. L. Morgan, D. M. Wilson, and V. M. Maher. Malignant transformation of human fibroblasts by transfected oncogenes. In: Cell Transformation and Radiation Induced Cancer. K. H. Chadwick, C. Seymour and B. Barnhart (eds.), Adam Hilger, Bristol, UK, pp. 75-84 (1989).

2. J. J. McCormick, D. G. Fry, P. J. Hurl in, T. L. Morgan, D. M. Wilson, and V. M. Maher. Malignant transformation of human fibroblasts by oncogene transfection or carcinogen treatment. In: Mutation and the Environment, Volume D: Carcinogenesis. M. L. Mendelsohn and R. J. Albertini (eds.), Wiley-Liss, New York, NY, pp. 195-205 (1990).

3. J. J. McCormick and V. M. Maher. Malignant iransformation of human fibroblasts in vitro. In: Environment and Genome. S. R. Bhattacharjee (ed.), India Environmental Mutagen Society, Calcutta, India, pp. 170-181 (1991).

4. J. J. McCormick and V. M. Maher. Malignant transformation of human fibroblasts in vitro. In: Neoplastic Transformation in Human Cell Culture. J. S. Rhim and A. Dritschilo (eds.), Humana Press, Inc., Totowa, NJ, pp. 347-357 (1991).

C. Abstracts of Papers Presented at National and International Meetings:

1. J. J. McCormick, and V. M. Maher. Malignant transformation of human fibroblasts by oncogene transfection or carcinogens. Environmental and Molecular Mutagenesis, 14, 125, 1989.

2. J. M. Scheid, J. J. McCormick, and V. M. Maher. Sequencing polymerase chain reaction amplified ras genes from transformed human fibroblasts to determine activation. Fourth Annual M.D./Ph.D. Student Conference, P-19, Aspen, C0, 1989.

3. J. J. McCormick, J.E. Dillberger, P. J. Hurlin, D.M. Wilson, D. G. Fry, and $V$. M. Maher. Malignant transformation of human fibroblasts by transfection of oncogenes. J. Cellular Biochemistry Supp1., 140, 11, 1990 .

4. J. Jankun, V. M. Maher, J. J. McCormick. Malignant transformation of human fibroblasts correlates with high levels of activity of a membranebound urokinase. J. Cellular Biochemistry Suppl. 140, 12, 1990.

5. J. J. McCormick, J. E. Dillberger, P. J. Hurl in, D. M. Wilson, D. G. Fry, and $V$. M. Maher. Malignant transformation of human fibroblasts by transfection of oncogenes. J. Cancer Research Clin. Oncol., Part I: 154, 1990.

6. D. Yang, V. M. Maher, and J. J. McCormick. Carcinogen-induced transformation of human fibroblasts. Proc. Amer. Assoc. Cancer Res., 31, $161,1990$. 
7. J. J. McCormick, and V. M. Maher. Analysis of the process of malignant transformation of human cells by oncogene transfectiun and carcinogen treatment. American Cancer Society, Michigan Division, Ypsilanti, MI, 1990.

8. J. Scheid, J. J. MCCormick, and V. M. Maher. Sequencing PCR-amplfied RAS genes to determine the role of mutational activation of RAS in the malignant transformation of human fibroblasts. American Cancer Society, Michigan Division, Ypsilanti, MI, 1990.

9. D. Yang, V. M. Maher, and J. J. McCormick. Carcinogen-induced transformation of human fibroblasts. American Cancer Society, Michigan Division, Ypsilanti, MI, 1990.

10. P. A. Ryan and J. J. McCormick. Analysis of tumor suppression at successive stages of transformation in a malignantly transformed line of human fibroblasts. Fifth Annual M.D./Ph.D. Student Conference, Aspen, CO, 1990.

11. J. Jankun, V. M. Maher, and J. J. McCormick. Urokinase receptor of human fibroblasts: Correlation between increase in receptor number and malignant phenotype. Tenth International Congress on Fibrinolysis, Indianapol is, IN, 1990.

12. J. M. Scheid, J. J. McCormick, and V. M. Maher. Sequencing PCR-amplified ras genes to determine their role in the malignant transformation of human fibroblasts. Midwest Student Medical Research Forum, 1991.

13. J. J. McCormick, D. Yang, and V. M. Maher. Genetic stability of human fibroblasts malignantly transformed in vitro. J. Cellular Biochemistry Supp 1. 150, 1991 .

14. J. Jankun, V. M. Maher, and J. J. McCormick. Quantitation of the urokinase and tissue plasminogen activator activity of malignantly transformed and normal human fibroblasts. J. Cellular Biochemistry Suppl. $150,140,1991$.

15. J. J. McCormick, D. Yang, C. Louden, S. Kohler, E. A. Potter, C. Spencer, and $V$. M. Maher. Malignant transformation of a human fibroblast cell strain, MSU-1.1, by the carcinogen benzo(a)pyrene-7,8,-diol-9,10-epoxide. Environmental and Molecular Mutagenes is 17, Supp1. 19, 49, 1991.

16. P. A. Ryan, V. M. Maher, and J. J. McCormick. Analysis of tumor suppression at successive stages of transformation in a malignantly transformed line of human fibroblasts. Workshop on Neoplastic Transformation in Human Cell systems in vitro: Mechanisms of Carcinogenesis, Georgetown University Medical Center, Washington, D. C., 1991.

17. J. M. Scheid, J. J. MCCormick, and V. M. Maher. Sequencing PCR-amplified ras genes to determine their role in the malignant transformation of human fibroblasts. Workshop on Neoplastic Transformation in Human Cell Systems in vitro: Mechanisms of Carcinogenesis, Georgetown University Medical Center, washington, D. C., 1991. 
18. D. Yang, C. Louden, S. Kohler, V. M. Maher, and J. J. Mccormick. Malignant transformation of a human fibroblast cell strain, MSU-1.1, by the carcinogen benzo(a)pyrene-7,8-diol-9,10-epoxide. Workshop on Neoplastic Transformation in Human Cell Systems in vitro: Mechanisms of Carcinogenesis, Georgetown University Medical Center, Washington, D. C., 1991.

19. J. Wray, J. M. Scheid, V. M. Maher, and J. J. McCormick. Establishment and tumorigenicity of cell lines derived from human tumors of mesenchymal origin. Workshop on Neoplastic Transformation in Human Cell Systems in vitro: Mechanisms of Carcinogenesis, Georgetown University Medical Center, Washington, D. C., 1991.

20. C. Lin, C-H. Pan, V. M. Maher, and J. J. McCormick. Malignant transformation of a human fibroblast cell strain by a transfected viral fes oncogene. Workshop on Neoplastic Transformation in Human cell Systems in vitro: Mechanisms of Carcinogenesis, Georgetown University Medsical Center, Washington, D. C., 1991.

21. C. Louden, D. Yang, S. Kohier, L. Milam, A. Zaccagnini, E. A. Potter, V. M. Maher, and J. J. McCormick. Histopathology and grade of tumors produced by oncogene transfection or carcinogen treatment in an infinite 1 ife span near diploid human fibrolbast cell strain (MSU-1.1). Workshop on Neoplastic Transformation in Human Cell Systems in vitro: Mechanisms of Carcinogenesis, Georgetown University Medical Center, Washington, D. C., 1991 .

22. D. S. Reinhold, R. R. Schilz, J. E. Dillberger, V. M. Maher, and J. J. Mccormick. Overexpression of multiple growth factor genes by fibrosarcoma-derived and other transformed human fibroblasts in culture. Workshop on Neoplastic Transformation in Human Cell Systems in vitro: Mechanisms of Carcinogenesis, Georgetown University Medical Center, Washington, D. C., 1991 .

23. J. J. McCormick, D. Yang, C. Louden, S. K. Kohler, E. A. Potter, C. Spencer, and V. M. Maher. Malignant transformation of a human fibroblast cel1 strain, MSU-1.1, by the carcinogen benzo(a)pyrene-7,8-diol-9,10epoxide (BPDE). Proc. Amer. Assoc. Cancer Res., 32, 140, 1991.

24. J. Jankun, V. M. Maher, and J. J. McCormick. Increase in the receptorbound urokinase plasminogen activator activity is a marker for malignant transformation of human fibroblasts. 3rd International Workshop on the Molecular and Cellular Biology of Plasminogen Activation, Denmark, 1991.

25. C. Lin, C-H. Pan, V. M. Maher, and J. J. McCormick. Malignant transformation of a human fibroblast cell strain by a transfected viral fes oncogene. American Cancer Society, Michigan Division, Detroit, MI, 1991.

26. D. S. Reinhold, R. R. Schilz, J. E. Dilliberger, V. M. Maher, and J. J. McCormick. Overexpression of multiple growth factor genes by fibrosarcoma-derived and other transformed human fibroblasts in culture. American Cancer Society, Michigan Division, Detroit, MI, 1991. 
27. P. A. Ryan, V. M. Maher, and J. J. McCormick. Analysis of tumor suppression at successive stages of transformation in a malignantly transformed line of human fibroblasts. American Cancer Society, Michigan Division, Detroit, MI, 1991.

28. J. M. Scheid, J. J. McCormick, and V. M. Maher. Sequencing PCR-amplified ras genes to determine their role in the malignant transformation of human fibroblasts. American Cancer Society, Michigan Division, Detroit, MI, 1991.

29. Q. Wang, V. M. Maher, and J. J. McCormick. Expression vectors with modulatable promoters and multiple selection markers. American Cancer Society, Michigan Division, Detroit, MI, 1991.

30. J. Wray, J. M. Scheid, V. M. Maher, and J. J. McCormick. Establishment and tumorigenicity of cell lines derived from human soft tissue tumors. American Cancer Society, Michigan Division, Detroit, MI, 1991.

31. D. Yang, C. Louden, D. Reinhold, S. Kohler, V. M. Maher, and J. J. McCormick. Malignant transformation of a human fibroblast cell strain, MSU-1.1, by the carcinogen benzo[a]pyrene-7,8-diol-9,10-epoxide. American Cancer Society, Michigan Division, Detroit, MI, 1991.

32. C. Lin, V. M. Maher, and J. J. McCormick. Maiignait transformation of a human fibroblast cell strain by a transfected viral fes oncogene. Proc. Amer. Assoc. Cancer Res. 33, 121, 1992.

33. C. Louden, V. M. Maher, and J. J. McCormick, Level of expression of the $\mathrm{H}$-ras oncogene determines the ability of human fibroblasts to become malignant. Proc. Amer. Assoc. Cancer Res., 33. 375, 1992.

34. D. S. Reinhold, R. J. Schilz, S. K. Kohler, V. M. Maher, and J. J. McCormick. Altered expression of multiple growth factor genes in fibrosarcoma-derived and other transformed human fibroblasts in culture. Proc. Amer. Assoc. Cancer Res. 33, 80, 1992.

35. P. A. Ryan, V. M. Maher, and J. J. McCormick. Suppression of the tumorigenicity of $\mathrm{H}-, \mathrm{V}-\mathrm{K}-$, or $\mathrm{N}$-ras oncogene-transformed malignant human fibroblast strains by fusion with their infinite life span, nontumorigenic parental strain, MSU-1.1. Proc. Amer. Assoc. Cancer Res. 33, $121,1992$.

36. Q. Wang, V. M. Maher, and J. J. McCormick. Analysis of changes in telomere DNA in human cell transformation. Proc. Amer. Assoc. Cancer Res. $33,121,1992$.

37. D. J. Yang, V. M. Maher, and J. J. McCormick. v-sis oncogene-induced transformation of human fibroblasts into cells capable of forming benign tumors. Proc. Amer. Assoc. Cancer Res. 33, 80, 1992.

38. J. J. McCormick and V. M. Maher. Malignant transformation of human fibroblasts in vitro. 1992 World 'Congress on Cell and Tissue Culture, Washington, D. C., 1992. 


\section{OVERVIEW OF RESEARCH ACCOMPLISHED}

\section{A. Background}

The overall goal of the proposed studies for the past reporting period was to carry out studies on the mechanism of malignant transformation of human fibroblasts. In 1988 we reviewed the 1iterature (McCormick and Maher 1988) and demonstrated by experimental evidence that no one had successfully transformed human fibroblasts in vitro, despite previous claims to the contrary. In some cases tumor-derived cells become mixed with normal cells making it appear that transformation had taken place. In other cases, the criteria used for transformation were insufficiently rigorous. It appeared to us that the main reason that malignant transformation in vitro had not been observed was that one needed an infinite 1 ife span cell strain that was normal in all other ways if one wanted to dissect the changes required for tumorigenicity. The Hayflick limit of 40 to 60 population doublings for human fibroblasts in culture allows such cells to undergo only two sequential clonal selections before they senesce. It appeared to us that the number of requires changes, in addition to immortality, was at least three and perhaps as many as six. By careful work, we were able to develop an immortal human fibroblast cell strain which is diploid, has normal growth control, and is nontumorigenic. We call this strain MSU-1.0. From this strain we derived a spontaneous variant (MSU-1.1) with two marker chromosomes and some aberration in growth control which allows it to grow at a moderate rate in medium without exogenous growth factors. This latter strain has been the central focus of our research during the past reporting period since it can be transformed to tumorigenicity by transfected ras oncogenes, as well as other oncogenes (see below).

In Section II above, we list the publications and the abstracts of reports presented at national and international meetings of research supported in whole of in part by this DOE arant. Below we give a brief summary of research 
conducted under each of the seven specific aims listed in the 1989 grant application. In many cases, the research is nearly ready for submission to a journal for publication, but lacks certain pieces of data. We have, therefore, requested the graduate students and the postdoctoral fellow carrying out the research to prepare a draft of the paper instead of merely writing a summary of their research. These drafts are included as part of this Progress Report. The obvious advantage to us of asking these young persons to prepare their report in the form of a manuscript is that it helps the individual worker to see more clearly the elements of the research that need completion. It also acts as a psychological stimulus to the workers because they realize that as soon as they obtain the needed piece of research data, the information can be slipped into the paper, and it will be ready for careful editorial work by the principal investigators and final submission. For the benefit of the DOE and/or reviewers, we briefly summarize each draft manuscript, note what studies remain to be completed, and reference the manuscript in the Appendix.

B. Malignant Transformation of MSU-1.1 Cells by Gamma Radiation (Original Aim A.) (Draft by Reinhold et al.)

We were successful in carrying out this aim and a draft manuscript is attached. We found that when these cells were exposed to cobalt 604.35 Gy of gamma radiation ( $-5 \%$ survival dose), allowed an eight day expression period, put into a focus assay, distinct foci were induced. No such distinct foci were seen with the unirradiated control MSU-1.1 cells. We isolated cells from a number of independent foci, recloned them in agarose to eliminate the nontransformed fibroblasts, isolated colonies able to form colonies in agarose, expanded these cells, and assayed the progeny for tumorigenicity. Five independent cell strains were tested and found to form tumors in athymic mice. Three different tumor histologies were observed i.e., round cell sarcomas, fibrosarcomas, and low grade 
spindle cell sarcomas. Each of these tumor histologies was found to be characteristic of the particular cell strain tested which suggests that in each case damage to a different gene was responsible for the specific tumor type. The fact that we now have evidence that our transformation assay will give a positive response with ionizing radiation forms the basis of our new application in which we propose to carry a detailed examination of the transforming effect of neutrons and gamma radiation, including a study of the dose rate effect. The draft manuscript on this work still requires: 1) a karyotype analysis of the transformed cel1s; and 2) completion of tumorigenicity studies (expected July 30 , 1992).

C. Correlation between Levels of ras Expression and Presence of Transformed Phenotypes Including Tumorigenicity, Using a Modulatable Promoter (Original Aim B.) (Draft by Louden et al.)

In published studies (Hurlin et a1. 1989; Wilson et al. 1992), we demonstrated that MSU-1.1 cells were able to be malignantly transformed by ras oncogenes only when they were expressed at high levels $(3$ to 7 times as much mutant ras protein as the total of all the ras proteins in the cells. We proposed, therefore, to examine the role of overexpression of an activated ras oncogene in malignant transformation by placing the ras oncogene under the control of a modulatable promoter. To do this, we engineered a plasmid in which the T24 ras oncogene was under the control of the metallothionein (MT) promoter. The plasmid al so contained the hygromycin resistance gene to provide a selectable marker. This allowed us to identify transfectants on the basis of drug resistance rather than expression of ras. Five independent transfectants were selected and expanded for in-depth study. All five cell strains had different base line levels of mutant $\mathrm{H}$-ras synthesis and all five exhibited upregulation of ras expression in a dose dependent manner when zinc was added at increasing 
concentrations. The cells' morphology change from spindle-shaped to rounded in response to the zinc. Expression of mutant ras following induction by zinc reached as high as 88 times that of the endogenous ras proteins.

To modulate expression of the T24 ras oncogene in cells in athymic mice that had been injected with the ras-transfected cells, we placed zinc sulfate in the drinking water. To get zinc levels of $30 \mu \mathrm{M}$ in the serum of the animals, it was necessary to give $1 \mathrm{mM}$ zinc sulfate in the drinking water. This level was toxic to the five to seven week old animals used in tumorigenicity assays. However, we found that if the adult female mice were exposed continuously to 1 mM zinc sulfate in their drinking water, this level was not toxic. When such animals were bred while being exposed to $1 \mathrm{mM}$ zinc sulfate and the newborn offspring continued to be exposed to zinc sulfate, the latter were tolerant of $1 \mathrm{mM}$ levels of zinc sulfate. Injection of MT-ras-transformed cells into these zinc-adapted animals resulted in tumors. The cells with the lowest expression level of ras formed benign spindle cell tumors. Those with higher levels of expression formed spindle cell sarcomas, and those with the highest levels of expression formed round cell sarcomas. Injection of MT-ras-transformed cells into animals not administered zinc resulted only in sporadic tumors after a very long latency period, suggesting that a second transforming event had to occur in these cells before they became malignant. Clearly the level of ras expression can control the tumor morphology.

A very important experiment was to determine whether removing zinc from the water of the animals that had formed tumors would cause the tumors to regress or remain static, or whether they would continue to grow. We expected that in the absence of zinc, the tumors would remain static, i.e., stop growing, but remain the same size. Instead, the tumors began to decrease in size within a week of removing the zinc. By six weeks, the tumors were completely gone, clearly 
indicating the necessity for continued ras expression. Histological examination of the tumors early in the regression period showed areas of necrosis with large numbers of lymphocytes in the area. From these observations, one cannot determine whether the cells stopped growing and the lymphocytes then moved in, or whether the lymphocytes actively killed the tumor cells.

The paper by Louden et al. is complete except for quantitative data on the level of expression of ras in the tumors. Experiments to obtain such data are now in progress.

\section{Relation between Specific Types of Sarcomas and Specific ras Oncogene} Expression (Original Aim C.) (Draft by Loudel, Oistan et al.)

Our previous studies suggested that activation of specific ras oncogenes correlated with the production of specific types of tumors. We, therefore, proposed to determine if the specific types of sarcomas produced with MSU-1.1 cells transformed with various oncogenes would reflect the specific oncogene transfectant rather than such factors as site of integration, plasmid vector used, etc. We also wanted to see if specific carcinogens gave specific types of tumors. However, as we considered these experiments, it became apparent that the somewhat muddled terminology used by pathologists to describe sarcomas would block clear interpreiation. Ciassical texts on soft tissue sarcomas use various terms to describe the same tumor and use a variety of descriptions to characterize the various types of sarcomas. Since sarcomas account for only $2 \%$ of human tumors, most pathologists dealing with human tumors see relatively few such tumors, and they seldom see more than one tumor from an individual patient. This may account for the lack of definition in describing sarcomas and lead to contradictions when tumors are assessed by a series of pathologists.

The original histopathology of the tumors that developed in our athymic mice during the past eight years was carried out by various collaoorating 
pathologists at different times. It seemed clear to us that we needed to review al1 the histopathology of all tumors the mice had developed with academically oriented pathologists to rigorously distinguish the $v_{u}$ ious tumor patterns. This we have done. Robert $W$. Dunstan, an Associate Professor in the Department of Pathology at Michigan State University, Calvert, Louden, DVM, a Ph.D. student in Pathology, and J. Justin McCormick reviewed more than 500 slides of tumors that arose from experiments using the MSU-1.1 cell strain. We examined the tumors to look for common patterns. Our conclusion was that the tumors fell into seven distinct patterns: round cell sarcomas, fibrosarcomas, malignant fibrous histiocytomas, rhabdosarcomas, myxoid sarccmas, spindle cell sarcomas, and fibromas (benign tumors). The attached paper by Louden, Dunstan et al., describing the tumor patterns has been prepared for submission to American Journal of Pathology. It requires some editorial work and then will be ready for submissi

E. Correlation of Genetic Changes in Fibroblastic Tumors with Malignancies (Original Aim E.) (Draft by Wray et al.)

One limitation of our studies on the in vitro transformation of human fibroblasts is that we compared the characteristics of our transformed MSU-1.1 cells with those of human fibrosarcoma-derived cell lines that had been in culture for many years. We validated the five such fibrosarcoma-derived cell lines available to us for their ability to form sarcomas in athymic mice, but there was still a possibility that, during the course of the years that they were passaged in culture, the cell lines had acquired some properties unrelated to the malignant state by which they differed from newly transformed cells. We, therefore, considered it important to examine soft tissue tumors taken directly from patients to characterize them and to develop new cell lines which had not been extensively passaged under noncontrolied conditions. This is an exunsive 
undertaking which has been carried out by Jeremy Wray as part of his Ph.D. thesis research. A draft of a manuscript is attached. Note that when a patient with a soft tissue sarcoma comes to a physician, most often the physician or surgeon is only sure that it is a tumor. The type and grade of the tumor can only be determined by taking a biopsy or by examining the tumor after it has been removed. With many such tumors, the surgeon proceeds immediately to remove the tumor. Histopathology on the tumor is available only 24-48 hr after surgery. Because we wanted to work with specimens from such tumors as soon as possible after they were removed from the patient, we were not able to know the outcome of the histopathology analysis until some time had passed. This means that we received a variety of human sarcomas, not just fibrosarcomas. However, since we were aware that human fibroblasts could form at least seven morphologically distinct tumors, such tumors were clearly relevant to our research.

In the course of these studies, Jeremy Wray became particularly interested in determining whether PDGF-B acts as an autocrine factor in sarcoma growth. Various strategies for carrying out such studies in vitro and in vivo are described in his paper. The draft of his manuscript which is included in this Report is lengthy, and represents a report which will need to be divided into several research papers depending upon the outcome of work that he is carrying out at present.

\section{F. Transformation of MSU-1.1 Cells by the sis Oncogene}

(Draft by Yang, Konler et. al.)

Normal human fibroblasts do not synthesize platelet-derived growth factor (PDGF), but respond to it. However, cells derived from several human fibrosarcomas express PDGF-B. To investigate the role of PDGF in the neoplastic transformation of human fibroblasts, we transfected a plasmid carrying the $v$-sis

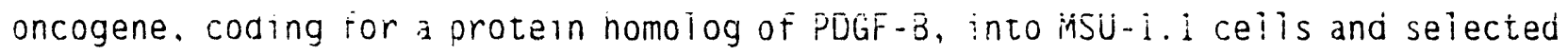


for drug resistance. Six clonal populations that were shown by Southern blotting to be independent transfectants were selected for study. All of them expressed $v$-sis gene mRNA and grew to a higher saturation density than the parental cell strain. Three expressed the $v$-sis gene at relatively low levels and did not exhibit growth factor independence. The other three expressed the $v$-sis gene at a high level, grew rapidly in medium lacking exogenous growth factors, and formed very large colonies in $0.33 \%$ agarose. These latter two characteristics could be el iminated by suramin, an inhibitor of growth factor binding. When these latter three cell strains were injected into athymic mice, they formed benign tumors that histologically are identical to human fibromas. The tumors came up in less than five weeks, and then the majority grew more slowly and eventually stopped growing. But among the tumors held in the mice for six months, focal areas of malignant cells developed. These experiments provide a unique model for benign tumor formation in tissue of mesenchymal origin in humans and show evidence of progression of tumors.

\section{G. Malignant Transformation of MSU-1.0 Cells (Original Aim D.) (Draft by Yang et al.)}

Once we had found that we could malignantly transform MSU-1.1 cells by high expression of a ras oncogene or by carcinogen treatment, it was of obvious interest to determine whether the precursor to MSU-1.1 cells, i.e., MSU-1.0 cells could also be transformed by transfected ras oncogenes. If this did not occur, it would indicate that one or more of the differences between MSU-1.0 cells and MSU-1.1 cells played a role in malignant transformation. Therefore, we tested this hypothesis by transfecting the same high expression ras oncogene vectors into MSU-1.0 cells that had caused the malignant transformation of MSU-1.1 cells. The MSU-1.0 cells gained some transformed characteristics, e.g., they formed smial i cuninies in agarose and exhibited modest growth in medium without exogenous 
growth factors. However, they were not tumorigenic in athymic mice. MSU-1.1 cells that exhibited these limited transformed properties also were nontumorigenic.

It was, therefore, of interest to try to cause MSU- 1.0 cells to acquire the phenotypic properties of MSU-1.1 cells. To do this we treated MSU-1.0 cells with the mutagenic BPDE, an activated metabolite of benzo(a)pyrene, and selected for cells that had "MSU-1.1-1ike" properties. The strategy was to select for focus formation or growth in agarose, using conditions that were less restrictive than those used for MSU-1.1 cells. Cells were isolated from these selections, grown to large populations, treated a second time with BPDE, and subjected to more restrictive selection conditions. This procedure was repeated a third time. (See page 17 of the manuscript by $Y a n g$ et al. for details, numbered page 143 because the draft was included as part of his thesis.) We were successful in isolating independent cell strains, each with specific in vitro properties of tumor-derived cells. Some of these strains are even more growth factor independent than MSU-1.1 cells, and some form colonies in agarose at a higher frequency than MSU-1.1 cells, but none have proven to be tumorigenic in athymic mice. Therefore, only MSU-1.1 cell strains will be used in the proposed studies of the transformation of human cells by neutron and gamma radiation.

Studies of the stepwise process by which MSU-1.0 cells can be made to acquire a fully malignant state will have to be investigated in the future using other sources of funding. As noted above, the draft of the manuscript is by Yang et a1. forms part of his doctoral thesis. Dr. Yang is staying on in the Carcinogenesis Laboratory for one year as a postdoctoral fellow to work on this project. For publication, he will need to have one or more of the BPDE-treated cell strains become tumorigenic. Alternatively, a careful characterization of the dominant-acting oncogenes and the suppressor genes would complete the manuscript. 
H. Correlation of Urokinase Plasminogen Activator ( $\beta-P A)$ with the Malignant Phenotype (Original Aim F.)

This study by Jankun et a1. was published in Cancer Research in 1991 (reprint included with this Report). The study demonstrates a perfect correlation between receptor-bound $\mu-P A$ activity and malignant transformation of cells in the MSU-1 lineage, regardless of whether they were transformed by transfected oncogenes or by carcinogens. Nonmalignantly transformed cells of the Tineage have markedly lower levels of $\mu-P A$ activity. Since we did not select for or against $\mu-P A$ activity, these results indicate that $\mu-P A$ activity is regulated secondarily as part of the process of malignant transformation.

I. Two Dimensional Gel Electrophoresis Studies of the Proteins of the Major Cell Strains of the MSU-1 Family of Cells

In collaboration with Dr. Mark Miller we have examined by 2-D gel electrophoresis, the differences in protein expression between the foreskinderived parental cell line from which MSU-1.0 cells arose, i.e., designated LGl and three immortal derivatives of LGI cells.

J. Correlation between Proteinase Activity Levels and Malignancy (Original Aim G.)

Robert Kenewel1, a medical student getting a Ph.D. has begin work on this project. However, because such students have a heavy course load ( $3 \frac{1}{2}$ years full time study towards the medical degree and the Ph.D. degree), he has just begun working in the laboratory to examine the problem using the RT-PCR procedure to determine what proteinases exhibit differences between the malignantly and nonmalignantly transformed cells of the MSU-1.1 family. 
V. Relationship Between the Research Accomplished during the Past Three Years and the Objectives for the Coming Three Years and Terminology used in this Proposal

The research we carried out during the first six years of this Grant has allowed us to prepare and to characterize the MSU-1.1 cell strain and determine that it can be transformed to the malignant state, not only by transfection of dominant-acting oncogenes, but also by treatment with chemical carcinogens, and most recently by gamma radiation. This research and our study of the types of tumors produced by the transformed human fibroblasts has laid the foundation for dose response and dose rate response curves for the transformation of human cells by neutrons and by gamma radiation. The ce' and molecular biology examination of the kinds of dominant oncogenes and suppressor genes that can effect this transformation prepared us to examine the question of the particular genes that play a causal role in the radiationinduced transformation of human cells into malignant cells.

Terminology Used in this Proposal

A recent exchange of views between Weinberg. Sager, Aaronson, and Hayf lich (In Vitro Cel1 Dev. Biol. 27: 3-6 1990; In Vitro Cel1 Dev. Bio1. 26:1-6 1989) on the proper terminology to be used to describe transformation of cells in vitro makes clear that the same terms may have opposite meanings to different investigators. For the sake of clarity, we have consistently used the terminology proposed by the Tissue Culture Association (In Vitro Cell Dev. Biol. 26: 97-101 1990) in this proposal and in all our published papers. For the convenience of reviewers, we provide the definitions of terms whose meanings are often less than certain.

1) Cell Line: A cell line arises from a primary culture at the time of the first successful subculture. The term cell line implies that cultures from it consist of lineages of cells originally present in the primary culture. The terms finite or infinite are used as prefixes if the status of the culture is known. If not the term line will suffice.

2) Cell strain: A cell strain is derived either from a primary culture or a cell line by the selection or cloning of cells having specific properties or markers. In describing a cell strain. its specific features must be defined.

3) Immortalization: The attainment by a finite cell culture, whether by perturbation or intrinsically, of the attributes of an infinite cell line. An immortalized cell is not necessarily one which is neoplastically or malignantly transformed.

4) Neoplastic Transformation: The acquisition, by cultured cells, of the property to form neoplasma, Denign or malignant, when inoculated into animals.

5) In Vitro Transformation: A neritable change, occurring in cells in culture, either intrinsically or from treatment with chemical carcinogens, oncogenic viruses, irradiation, transfection with oncogenes, etc. and leading to the acquisition of altered morpnological, antigenic, neoplastic, proliferative or other properties.

5) Malignant transformation (In Vitro): The acquisition, by cultured cells, of the oroderty to form malignant tumors, when inoculated into animals. 


\section{STUDENTS TRAINED AND POSTDOCTORAL TENURES COMPLETED DURING THIS REPORTING PERIOD}

A. During the past three years, one of the postdoctoral research associates who was supported by this Grant completed his training in the Carcinogenesis Laboratory and accepted a permanent position.

Name of Research Associate New Position Date

$\begin{array}{lll}\text { Jerzy Jankun, Ph.D. } & \text { Assistant Professor } & 1990\end{array}$

Chemistry Department

University of Toledo

Toledo, $\mathrm{OH}$

B. In addition, two graduate students supported by this Grant completed the research for the Ph.D. degree and one graduate student completed research for the M,S. degree and accepted permanent or postdoctoral positions.

Name of Graduate Student New Position Date

Tony Fox, Ph.D. Staff Scientist

Chemical Industries Institute

of Toxicology

Research Triangle Park, N.C.

Dajun Yang, Ph.D.

Postdoctoral Research Associate

1992

Carcinogenesis Laboratory

Michigan State University

East Lansing, MI

Chin-Huei Pan, D.V.M./M.S.

Research Assistant

Lawrence Berkeley Laboratory

1990

University of California-Berkeley

Berkeley, CA

c. The following postdoctoral research associates also were receiving training in the Carcinogenesis Laboratory conducting research supported by other sources of funds. (These persons benefitter only indirectly from the past support of this D.O.E. Grant or the predecessor Contract in providing equipment, etc.)

\section{Name of Research Associate}

Chia-Miao Mah, M.D./Ph.D.

(Molecuíar Biology)

W. GTenn McGregor, M.D.

(Medicine)

Rebecca Odenwaller, Ph.D

(Chemistry)

David S. Reinhold, Ph.D

(Biochemistry)

Robert J. Steighner, Ph.D

(Pharmacology/Toxicology)

Qingping Wang, Ph.D.

(Biochemistry)

\section{Institution Granting Degree}

Michigan State University

East Lansing, MI

University of Michigan

Ann Arbor, MI

Wayne State University

Detroit, MI

Case Western Reserve University

Cleveland, $\mathrm{OH}$

Virginia Commonwealth University

Richmond, VA

Michigan State University

East Lansing, MI

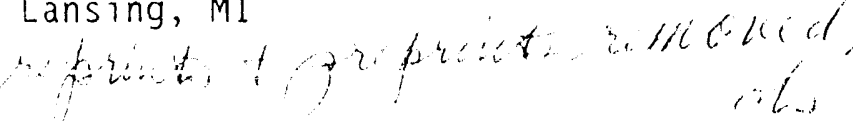


DATE FILMED 215193 
